\title{
GÊNERO E SUPER-HERÓIS: O TRAÇADO DO CORPO MASCULINO PELA NORMA ${ }^{1}$
}

\author{
Adriano Beiras \\ Alex Lodetti \\ Arthur Grimm Cabral \\ Maria Juracy Filgueiras Toneli \\ Pablo Raimundo \\ Universidade Federal de Santa Catarina, Florianópolis, Brasil
}

RESUMO: As Histórias em Quadrinhos de super-heróis ganham vida na imaginação dos leitores, estabelecendo fortes ligações com seu cotidiano. Um corpo musculoso e viril vem historicamente se tornando o referencial de corporeidade masculina, enquanto corpos que desviam desse modelo são comumente satirizados ou excluídos da mídia. Este ensaio objetiva discutir as formas de representação do corpo masculino nas HQs da DC Comics, especificamente nas histórias de Superman e de Batman, conforme a caracterização de personagens como "heróis", "vilões" ou "coadjuvantes". Nossa premissa é a de que estas caracterizações remetem a tendências distintas de representação dos corpos, (re)produzindo normas sociais e valores de estética sobre as corporeidades.

PALAVRAS-CHAVE: Histórias em quadrinhos; masculinidades; corporeidade; mídia.

\section{GENDER AND SUPERHEROES: \\ THE MASCULINE BODY TRACED BY THE NORM}

ABSTRACT: Superhero comic books gain life in the reader's imagination, establishing strong connections to their daily life. A muscular and virile body has historically become the reference for male corporeality, while bodies that deviate from this are commonly satirized or excluded from the media. This essay intends to discuss the forms of representation of the male body in $D C$ comic books, specifically Superman and Batman, according to the portrayal of characters as 'heroes', 'villains' or 'supporting characters'. Our premise is that these roles relate to distinct tendencies for the depiction of bodies, (re)producing social norms and aesthetic values upon corporealities.

KEYWORDS: Comic books; masculinities; corporeality; media.

\section{Prelúdio}

Ao mesmo tempo refletindo e construindo realidades, as Histórias em Quadrinhos de super-heróis ganham vida na imaginação de seus leitores, estabelecendo fortes ligações com o mundo cotidiano destes. A exemplo de outras mídias, as HQs freqüentemente se prestam a representar ideais, valores, normas e padrões de conduta da sociedade de consumo, que servem à manutenção dos poderes instituídos; ainda que, por vezes, também sirvam à denúncia destes mesmos mecanismos. A construção dessas narrativas está diretamente ligada à experiência concreta de seres humanos -seus autores e editores, em relação com a comunidade leitora - (re)produzindo determinadas formas de existir e funcionando como mediação do real.

Um corpo musculoso, forte e viril (tirado de academias, imagens publicitárias e veículos de entretenimento) vem historicamente se tornando o referencial de corporeidade masculina, enquanto corpos que desviam deste padrão são comumente satirizados ou mesmo excluídos da mídia. Segundo padrões normativos da atualidade, músculos são indicativos de masculinidade (Glassner, 1989), atestando um ideal de força e virilidade, potencializado pela mídia sobre o imaginário de jovens homens. No caso das HQs de super-heróis, percebe-se uma heterogeneidade de representações corporais masculinas que demonstram variar de acordo com a caracterização do personagem.

Considerando esse contexto, buscamos refletir sobre as diferentes formas de representação do corpo masculino nas HQs da DC Comics, mais especificamente as de Superman e as de Batman, conforme a caracterização de personagens como "heróis", "vilões" ou "coadjuvantes". Nossa premissa é a de que estas caracterizações remetem a tendências distintas de representação dos corpos, refletindo e construindo normas sociais e valores de estética sobre as diversas possibilidades de corporeidade.

Masculinidades são aqui entendidas como construções históricas e sociais, como um conjunto de atributos que significam o masculino. Da mesma forma, corporeidade é entendida como um espaço social, significado a partir de elementos sócio-históricos e culturais que dão sentidos e inteligibilidade ao corpo.

Através deste ensaio, pretendemos compreender quais seriam os modelos de masculinidade implícitos nos quadrinhos estudados, bem como determinar de que forma são representados aqueles personagens que se aproximam 
e aqueles que se desviam deste referencial. Considerando a possibilidade dessas normas sociais e valores de estética reverberarem no imaginário masculino, questionamos também de que maneira este imaginário se apropria dos mesmos. Todas essas análises são construídas e propostas a partir da matriz teórica histórico-crítica, bem como a partir das teorias de gênero.

\section{Esquadrinhando o Masculino}

A pesquisa em corporeidade masculina permanece um campo pouco explorado e, por vezes, conflitante em suas análises. Neste cenário, verifica-se também uma lacuna no estudo do masculino nas revistas em quadrinhos, que se revela surpreendente quando consideramos a afirmação de Brown (1999, p. 2) de que "classical comic book depictions of masculinity are perhaps the quintessential expression of our [north american] cultural beliefs about what it means to be a man". ${ }^{2}$

A rigidez de fórmulas (clichês e estereótipos) característica do universo dos super-heróis norte-americanos permite que este continue sendo predominantemente habitado por homens brancos (Palmer-Mehta \& Hay, 2005), com mulheres como coadjuvantes - saudáveis e atraentes ou velhas e frágeis, mas raramente como iguais. Imagens de anti-feminismo e de racismo ainda são lugar-comum, visto que geralmente não há justa representação de diferentes etnias e da mulher, cabendo a estes papéis secundários, figurativos ou vilanescos. Notável também é a relação de mortes entre homens brancos de um lado e mulheres, minorias e a comunidade GLBT de outro, pois geralmente são os corpos deste segundo grupo aqueles que sofrem pelos problemas sociais abordados nessas revistas.

Além da recorrente presença de valores anti-feministas e racistas, verifica-se nas narrativas estudadas a emergência de determinados padrões de corporeidade. Brown (1999) emprega o caso da Image Comics para ilustrar esse fenômeno. Desde sua fundação, esta editora refletiu um novo padrão de corporeidade masculina através da utilização ostensiva de significadores de masculinidade: o corpo hipertrofiado, com uma massa de veias e músculos, assim como a apresentação de luta após luta, sem qualquer crítica ou reflexão a respeito por parte dos personagens.

A imagem corporal é definida por McKay, Mikosza e Hutchins (2005) como uma imagem psíquica construída a partir de um corpo físico pela apropriação de significados simbólicos construídos socialmente, e como tal estando em contínua transformação. Houve, por exemplo, a mudança do significador primordial de masculinidade: no passado, a barba e outros pêlos corporais indicavam a maturidade e virilidade daqueles que as possuíssem, enquanto nos dias atuais essa significação é atribuída ao modelo mesomórfico de corpo e à musculosidade.
Um estudo conduzido por Wienke (1998) abordou o caráter central dos músculos enquanto representantes de masculinidade na cultura popular norte-americana. Utilizando entrevistas em profundidade, analisadas via interpretação narrativa, o autor concluiu que quase todos os sujeitos pesquisados aspiravam possuir um corpo mesomórfico e tinham organizado suas práticas corporais a partir de uma destas três estratégias: "confiança", "reformulação" ou "rejeição". A maioria dos informantes adotava a prática de "confiança", identificando-se com e buscando ativamente alcançar o modelo muscular firme e volumoso associado à masculinidade. Aqueles que organizavam suas práticas através de "reformulação" também desejavam esse corpo normativo, porém entendiam que não poderiam atingi-lo, desenvolvendo, dessa forma, estratégias alternativas para incorporar autoridade, força e autocontrole. Finalmente, alguns homens tinham, de fato, "rejeitado" o ideal muscular, encarando-o como um produto de referenciais irreais ou datados.

De forma análoga, considerando a presença massiva e a glamourização do modelo corporal musculoso e mesomórfico nas HQs de super-heróis, bem como a proliferação do mesmo como valor cultural nos últimos anos, podemos presumir que as estratégias de práticas corporais apontadas por Wienke (1998) também se apliquem aos consumidores dessas histórias.

Um aspecto fundamental para a identificação do leitor com a figura do super-herói, levantado por Brown (1999), seria a dualidade de masculinidade presente nesse tipo de personagem. Enquanto o alter-ego heróico personifica a força, a confiança e o poder de um ideal máximo de masculinidade, a identidade secreta retém as vulnerabilidades, inseguranças e suavidades do "homem comum", numa dinâmica que potencializa a fantasia ao mesmo tempo em que a aproxima do "leitor comum". Na faceta heróica, percebe-se que as características ocultas são justamente aquelas que expressam vulnerabilidade, o que pode ser entendido como um reflexo do medo do não-masculino permeando essas narrativas. ${ }^{3}$ Assim, as revistas em quadrinhos encenariam continuamente uma ambivalência de masculinidade, vivida pelos super-heróis como uma máscara, levando-os a manter duplas identidades, a fim de ocultar certos atributos e expressar outros de forma enfática.

The stories of super-hero has always been a wishfullfilling fantasy for young men... around the male daydream that, if we could just find the right word, the right experimental drug, the right radioactive waste, then we too might instantly become paragons of masculinity (Brown, 1999, p. 30). ${ }^{4}$

A posição masculina dentro das HQs, ao ser analisada criticamente, de forma análoga a como a feminilidade dentro da mídia foi desconstruída pelo movimento feminista, não nos revela uma posição de sujeito definida e 
concreta, mas sim uma performance cuidadosamente orquestrada (Brown, 1999).

A problemática da orquestração de um sujeito generificado é também levantada por Butler (1993), em sua noção de performatividade, segundo a qual masculinidades e feminilidades são construídas a partir da sedimentação de ações no cotidiano 5 . Ideais regulatórios produzem os corpos ao mesmo tempo em que estes (re)produzem tais ideais; a atribuição de diferentes valores a determinados corpos fundamenta a abjeção daqueles corpos que se afastam dos padrões normativos. Nesse sentido, conforme os referenciais de masculinidades encontrados nas revistas em quadrinhos de super-heróis, os corpos de vilões e personagens coadjuvantes tendem a ser representados como abjetos - enquanto vis, grotescos ou desprovidos de poder.

Brown (1999) desenvolve sua leitura de gênero apenas sobre os super-heróis dessas narrativas, atribuindo exclusivamente a eles a influência social dos quadrinhos. Entretanto, podemos questionar qual a relação que se estabelece entre os leitores e aqueles personagens "secundários", que utilizam seus super-poderes para fins moralmente repreensíveis, ou que são desprovidos de qualquer habilidade extraordinária. Lembremos que a construção social da masculinidade não se orienta apenas pelas figuras com as quais o sujeito se identifica, mas também por aquelas das quais ele se diferencia (Connel, 2005). Do mesmo modo, é possível problematizar os modelos de relações sociais implícitos na interação de personagens protagonistas, antagonistas e coadjuvantes.

Em nossa leitura de relações sociais, estas são incessantemente atravessadas por questões de gênero. A constituição de um sujeito generificado é culturalmente complexa, especialmente quando trabalhamos com uma perspectiva de subjetividade enquanto múltipla e potencialmente contraditória (Moore, 2000). Uma noção estanque de subjetividade simplesmente não dá conta de elucidar todos os movimentos e discursos da esfera de um sujeito inserido em sociedade e atravessado pelo gênero. Como argumenta Moore (p. 20), "ninguém pode jamais estar plenamente consciente das condições de sua própria construção".

Na discussão da corporeidade masculina nas HQs, partimos de uma análise crítica da construção do corpo. Concebido aqui como "objeto social e discursivo... vinculado à ordem do desejo, do significado e do poder", o corpo carrega em si todo um arremate de significadores que produzem e re-produzem a ordem social estabelecida (Grosz, 2000, p. 77).

Connell (1997) define masculinidades como configurações de práticas sociais que se referem a corpos masculinos, estando elas tanto relacionadas à ordem simbólica e institucional de nossa sociedade como aos aspectos individuais dos sujeitos nela inseridos. Este autor reconhece ainda a noção de "múltiplas masculinidades" (Connell, 1995), hierarquizadas a partir de relações de poder e no centro das quais existiria uma "masculinidade hegemônica" - um conjunto de práticas e valores com a função de garantir a posição dominante dos homens e a subordinação das mulheres.

Um modelo de masculinidade hegemônico também é trabalhado por Kimmel (1997) e por Vale de Almeida (1995), correspondendo a um homem branco, ocidental, de classe dominante, provedor, heterossexual, forte e viril. Tais perspectivas de masculinidade sugerem que a disseminação de um modelo normativo em comerciais, brinquedos, filmes, desenhos animados e, como enfocado aqui, revistas em quadrinhos, reforçaria a busca de muitos jovens por esse ideal.

Sobre o papel específico das revistas em quadrinhos de super-heróis em relação ao universo masculino, Brown (1999) aponta que:

Superhero comics have always relied on the notion that a superman exists inside every man, and while the readers are well aware of this most fundamental convention, they are also aware that several new and incredibly popular comics are erasing the ordinary man underneath in favor of an even more excessively powerful and one-dimensional masculine ideal (p. 2). ${ }^{6}$

\section{Homem-de-Aço versus Cavaleiro das Trevas}

No sentido de desenvolver uma breve análise de elementos observados por nós enquanto leitores de quadrinhos, selecionamos para discussão os personagens Superman e Batman, ambos ícones culturais e propriedades intelectuais da $D C$ Comics. A escolha pela editora $D C$ deve-se à sua longevidade e identificação com personagens clássicos e tradicionais. A história dessa empresa confunde-se com a própria evolução do mercado de quadrinhos nos EUA e no mundo.

A escolha pelo personagem Superman se impôs por sua popularidade, longevidade e pelo fato do mesmo representar ostensivamente um ideal de homem. Como seu próprio nome indica, Superman sugere superioridade em relação aos outros homens, apresentando-se como modelo e referência que se verificará tanto em suas capacidades físicas como em sua disposição de caráter. Alienígena enviado à Terra ainda bebê e criado por um casal de fazendeiros do Meio-Oeste dos EUA, Clark Kent manifesta e desenvolve poderes sobre-humanos, resultantes da interação de sua origem extra-terrena com o ambiente de nosso planeta. Sugere-se, em suas narrativas, que a educação exemplar oferecida por uma família tipicamente norteamericana foi decisiva para o emprego ético dessas habilidades. Dentro de seu próprio universo ficcional, Superman 
- também conhecido como "Homem de Aço" - é considerado o exemplo máximo de poder sobre a matéria, um poder convenientemente associado à moralidade e à sabedoria de seu uso. Esse apelo simbólico se estende ao público que consome suas histórias. Publicado desde 1938, Superman é considerado o primeiro super-herói, "pai" daqueles que o seguiram. Através dos anos, suas histórias foram adaptadas para todos os veículos de comunicação de massa-jornais, revistas, rádio, $\mathrm{TV}$, cinema, videogames, jogos de computador e livros.

Batman rivaliza em popularidade e longevidade com Superman, também tendo sido extensivamente adaptado para outras mídias. Suas histórias, publicadas desde 1939, apresentam um discurso próprio e distinto. Desprovido de super-poderes inerentes, Bruce Wayne é um "self-made man", alguém que desenvolveu ao máximo suas capacidades físicas e intelectuais, ao mesmo tempo em que se vale de um poder financeiro herdado para reunir uma infinidade de aparatos tecnológicos que o auxiliam em sua cruzada. O objetivo desta é o combate ao crime, motivado pelo trauma infantil do assassinato de seus pais durante um assalto. Sob a figura do morcego, animal noturno associado ao terror, Batman - por vezes referido como "Cavaleiro das Trevas" - emprega iconografias e estratégias que o aproximam da figura clássica de vilão. Suas narrativas, entretanto, oferecem aos leitores caracterizações que o distinguem de seus antagonistas: ele nunca sacrifica vidas humanas e é sempre motivado por um ideal de justiça.

É possível identificar diversos contrastes entre os universos e discursos de Superman e de Batman. Ainda que nem todos esses elementos estivessem presentes desde as primeiras histórias desses personagens, com o tempo eles vieram a se estabelecer e a se consolidar nas narrativas, a ponto de atualmente serem facilmente reconhecíveis e associáveis aos respectivos protagonistas.

Assim como as narrativas de Superman são herdeiras dos contos de fantasia e ficção científica, as de Batman se remetem aos contos de detetive e mistério. Metrópolis, sede das aventuras do Superman adulto, é a "cidade do amanhã", geralmente retratada de dia e em si mesma um ideal, pela urbanidade, magnitude e luminosidade do seu projeto. Gotham City, lar de Batman, é a cidade gótica por excelência, um meio urbano corrupto e decadente, geralmente retratado à noite e povoado de figuras ardilosas e grotescas. Superman luta pela manutenção do sistema em que vive, enquanto Batman freqüentemente entra em atrito com esse mesmo sistema para alcançar sua noção de justiça. Inclusive, através dos anos e, sobretudo, a partir da década de 80 , as histórias que encenavam encontros entre esses personagens passaram a explorar conflitos entre eles, baseados nas diferentes motivações e estratégias de atuação. Também sugerindo esse contraste de universos, a partir de outubro de 2003 passou a ser publicada nos EUA a revista mensal Superman/Batman, cujo principal mote é justamente a interação entre os personagens e o inevitável atrito decorrente.

Apesar de apresentarem representações corporais similares, Superman e Batman oferecem diferentes discursos sobre masculinidade. Um dos aspectos que demonstra esta diferença é o grau de violência adotado em relação aos criminosos, que vem a ser inversamente proporcional ao seu próprio nível de poder. Enquanto Superman é muito mais poderoso e invulnerável se comparado a Batman, ele é também mais condescendente com seus vilões. Batman, que possui habilidades (supostamente) dentro do alcance humano, geralmente inflige mais dor e medo em seus antagonistas do que Superman o faz. Tal contraste pode ser relacionado à tese de Messerschmidt (2000) sobre masculinidades e violência, em que esta última é encarada como uma forma de "compensar" a falta de poder nas relações cotidianas. Essa impotência envolve aquilo a que o autor se refere como "masculine challenges", ou seja, situações nas quais a identidade masculina é posta em dúvida. Assim, podemos inferir que Superman, não apenas super-poderoso mas também afetuosamente educado por seus pais adotivos, pode dar-se ao luxo de não empregar violência excessiva, enquanto Batman, com suas limitações humanas e diante da falta de acompanhamento parental, precisa recorrer à violência como estratégia de atuação.

\section{Grandes Poderes, Grandes Responsabilidades}

Corpos masculinos são sempre corpos inseridos na história e na cultura. Esta afirmação torna-se especialmente relevante quando lidamos com a representação corporal em personagens fictícios. Seria tarefa infrutífera discutir esses corpos a partir de uma suposta concretude imagética, desconsiderando o contexto histórico que ocupam, as normas e valorações sociais a eles atribuídos.

No caso específico das HQs estudadas, as imagens corporais estão sempre implicadas no enredo: corpos que salvam o mundo (ou os EUA), corpos que tentam destruí-lo, corpos que são defendidos por um herói, corpos que apenas figuram na história, etc. Observamos, nessas narrativas, que diferentes funções são atribuídas a diferentes corpos, e que tais atribuições estariam, por sua vez, relacionadas a valores e normas histórica e culturalmente construídas em torno dos sujeitos masculinos.

A análise dos corpos dos personagens nessas HQs revela tendências distintas e significativas entre os mesmos. Os super-heróis, por exemplo, geralmente apresentam um status corporal padronizado e enfático: os corpos masculinos são viris e musculosos, enquanto os femininos são esguios e intensamente erotizados. 
Nossa premissa é a de que as representações corporais desses personagens remetem, ao mesmo tempo, a uma instância ético-moral e a outra de poder de ação. Esta espécie de dialética entre poder e moralidade é explicitamente ilustrada por um lema recorrente nas revistas de Spider-man, personagem da editora Marvel Comics, desde sua primeira história, publicada em 1962: "com grandes poderes, vêm grandes responsabilidades".

O poder de ação dos personagens nas HQs de superheróis é tipicamente retratado através do modelo mesomórfico de corpo e da musculosidade. Tanto em heróis como em vilões, estes atributos são lugar-comum, enquanto os personagens coadjuvantes geralmente detêm (por comparação) corpos menos desenvolvidos. Desse modo, os personagens "bons" que possuem alto poder de ação são caracterizados como "super-heróis", ao passo que os personagens "maus" com esse nível de poder são caracterizados como "super-vilões". Os demais personagens são considerados coadjuvantes, ou seja, independentemente de seu posicionamento ético-moral, suas ações não costumam determinar o curso dos enredos. Como exemplos de personagens coadjuvantes, temos Jimmy Olsen, colega de Superman, e Alfred Pennyworth, mordomo de Batman.

A musculosidade masculina teria, assim, a função de destacar os personagens principais em relação àqueles menos atuantes e menos relevantes. Podemos pensar essas representações corporais como metáforas das relações sociais hierárquicas entre masculinidades apontadas por Connell (1995), segundo as quais apenas alguns homens centralizariam o poder na sociedade.

Outros elementos estéticos se fazem presentes na caracterização do posicionamento ético-moral desses personagens. Enquanto os corpos dos heróis são costumeiramente representados de forma mais simétrica, dentro de padrões normativos de saúde e beleza, os corpos dos vilões freqüentemente carregam traços ou atributos que os desviam destes mesmos padrões, tais como cicatrizes, deficiências físicas ou feições associadas ao grotesco.

Como exemplos de vilões, temos Apocalypse (que "matou" Superman) e Bane (que quebrou a coluna de Batman). A exemplo dos correspondentes heróis, ambos apresentam um corpo enfático e musculoso, mas num grau massivo, grotesco. A ameaça e vilania destes personagens também são expressas através de outras condições corporais: no caso de Apocalypse, as afiadas protrusões ósseas que emergem de suas articulações; no caso de Bane, os tubos intravenosos que injetam a droga anabolizante da qual é dependente.

Podemos inferir que essas caracterizações de personagem via representações corporais contribuem para uma construção sígnica singular de corporeidade masculina: musculosidade associada à poder de ação e protagonismo, e corpo mesomórfico como padrão normativo de beleza.

\section{Epílogo}

Neste ensaio procuramos abordar algumas questões relativas ao papel das HQs de super-heróis na constituição de ideais e sentidos de masculinidades. Como resultado de nossas análises, podemos afirmar com certa propriedade que existe um modelo, fortemente colocado nessas narrativas, do que significa ser um homem e do que se espera de um homem em nossa sociedade. Por extensão, aqueles que se desviam destes padrões geralmente surgem como coadjuvantes, sem capacidade de ação transformadora, como alívio cômico e objeto de sátira, ou ainda como vilões, personificando a antítese ou corrupção do modelo proposto.

Considerando o contexto norte-americano em que os quadrinhos em questão foram criados, podemos identificar uma série de valores associados à masculinidade, dentre os quais força física, virilidade, poder econômico, racionalidade, controle emocional, honra, lealdade e a predominância masculina na esfera pública. Estes valores coexistem, sobrepondo-se e dialogando, freqüentemente em contradição. Percebe-se que heróis e vilões, figuras centrais das HQs estudadas, tendem a refletir e cristalizar esses valores, que variam em natureza e em grau conforme a caracterização do personagem ou a linha narrativa.

Análises e discussões sobre as origens, contextos, fórmulas e convenções das HQs são comumente encontradas em sites especializados na internet ou mesmo nas seções de cartas das revistas em questão, o que demonstra as possibilidades de diálogo e de reflexão dos leitores sobre a mídia que estão consumindo. A exposição às HQs de super-heróis pode, presumivelmente, imprimir sobre a constituição dos sujeitos ideologias e padrões de conduta. Entretanto, não é possível afirmar categoricamente que exista uma relação direta entre aquilo que alguém consome e aquilo que alguém se torna. Portanto, embora seja possível supor relações de influência recíproca entre as HQs de super-heróis e os modelos de masculinidades atuantes no imaginário masculino, pesquisas específicas se fazem necessárias para a investigação de tais relações.

\section{Notas}

\footnotetext{
Uma primeira versão deste artigo, em inglês, foi apresentada no II International Colloquium of Studies on Men and Masculinities III Coloquio Internacional de Estudios sobre Varones y Masculinidadesy I Congreso Nacional de la Academia Mexicana de Estudios del Género de los Hombres, realizado na cidade de Guadalajara, México. Outra versão, reduzida e em português, foi apresentada no Seminário Internacional Fazendo Gênero 7 , na cidade de Florianópolis, Brasil. Ambas as versões foram publicadas como trabalhos completos nos anais desses eventos, durante o ano de 2006.

2 "Representações de masculinidade em histórias em quadrinhos clássicas são, talvez, a expressão arquetípica de nossos valores
} 
culturais (norte-americanos) sobre o que significa ser um homem" (tradução dos autores).

3 Citando Brown: "in general, masculinity is defined by what it is not, namely 'feminine', and all its associated traits - hard not soft, strong not weak, reserved not emotional, active not passive" (1999, p. 2). “em geral, masculinidade é definida pelo que nãoé, nominalmente 'feminino', e todos os seus traços associados duro não mole, forte não fraco, reservado não emocional, ativo não passivo" (1999, p. 2, tradução dos autores).

4 "As histórias de super-heróis sempre foram uma forma de realização de desejos fantasiosos para jovens homens... em torno do sonho masculino de que, se conseguíssemos achar a palavra certa, droga experimental ou lixo radioativo, então nós também poderíamos nos tornar instantaneamente referenciais de masculinidade" (tradução dos autores).

5 Ver Butler (Bodies that matter, New York: Routledge, $1993 \mathrm{e}$ Gender trouble: Feminism and the subversion of identity. New York: Routledge, 1990).

6 "Quadrinhos de super-heróis sempre se apoiaram na noção de que existe um super-homem dentro de cada homem, e apesar de os leitores reconhecerem essa convenção fundamental, eles também reconhecem que muitos quadrinhos novos e incrivelmente populares estão apagando o homem comum em favor de um ideal masculino ainda mais poderoso e unidimensional" (tradução dos autores).

7 O personagem "retornaria à vida" em edições futuras.

\section{Referências}

Brown, J. A. (1999). Comic book masculinity and the new black superhero. African American Review, 33(1), 25-42.

Butler, J. (1990). Gender trouble: Feminism and the subversion of identity. New York: Routledge.

Butler, J. (1993). Bodies that matter: On the discursive limits of "sex". New York: Routledge.

Connell, R. W. (1995). Masculinities. Berkeley, CA: University of California Press.

Connell, R. W. (1997). La organización social de la masculinidad. In T.Valdés \& J. Olavarría (Eds.), Masculinidad/es (pp. 31-48). Santiago, Chile: FLACSO/ISIS Internacional, Ediciones de lãs Mujeres.

Glassner, B. (1989). Men and muscles. In M. S. Kimmel \& M. A. Messner (Eds.), Men's Lives (pp. 252-261). Boston: Allyn and Bacon.

Grosz, E. (2000). Corpos reconfigurados. Cadernos Pagu, 14, 45-83.

Kimmel, M. S. (1997). Homofobia, temor, vergüenza y silencio em la identidad masculina. In T. Valdés \& J. Olavarría (Eds.), Masculinidad/ es (pp. 49-62). Santiago, Chile: FLACSO/ISIS Internacional, Ediciones de las Mujeres.

McKay, J., Mikosza, J., \& Hutchins, B. (2005). "Gentlemen, the lunchbox has landed" Representations of masculinities and men's bodies in the popular media. In R. W. Connell \& M. Kimmel (Eds), Handbook of Studies on Men and Masculinities (pp. 270-288). Thousand Oaks, CA: Sage.
Messerschmidt, J. W. (2000). Becoming "real men": Adolescent masculinity challenges and sexual violence. Men and Masculinities, 2(3), 286-307

Moore, H. (2000). Fantasias de poder e fantasias de identidade: gênero, raça e violência. Cadernos Pagu, 14, 13-44.

Palmer-Mehta, V., \& Hay, K. (2005). A superhero for gays?: Gay masculinity and green lantern. The Journal of American Culture, 28(4), 390-404.

Vale De Almeida, M. (1995). Senhores de si. Uma interpretação antropológica da masculinidade. Lisboa, Portugal: Fim de Século.

Wienke, C. (1998). Negotiating the male body: Men, masculinity, and cultural ideals. The Journal of Men's Studies, 3(6), 255-282.

Adriano Beiras é Psicólogo, graduado pela UFSC e Mestre em Psicologia pela mesma instituição. Pesquisador do Núcleo Margens (Modos de Vida, Família e Relações de Gênero), do Departamento de Psicologia da UFSC.

Alex Simon Lodetti é Psicólogo, graduado pela UFSC e Mestrando do Programa de Pós-Graduação em Psicologia da mesma instituição. Pesquisador do Núcleo Margens (Modos de Vida, Família e Relações de Gênero), do Departamento de Psicologia da UFSC.

Arthur Grimm Cabral é Psicólogo, graduado pela UFSC e Mestrando do Programa de Pós-Graduação em Psicologia da mesma instituição. Pesquisador do Núcleo Margens (Modos de Vida, Família e Relações de Gênero), do Departamento de Psicologia da UFSC.

Pablo Raimundo é Psicólogo, graduado pela UFSC e Mestrando do Programa de Pós-Graduação em Psicologia da mesma instituição. Atualmente também conclui Especialização em Psicologia Clínica no Instituto Gestalten, em Florianópolis.

Maria Juracy Filgueiras Toneli é Psicóloga, Doutora em Psicologia pela USP, Pesquisadora do CNPq e Professora Associada I da UFSC, onde leciona e orienta em graduação e pós-graduação.

\section{Gênero e super-heróis: \\ o traçado do corpo masculino pela norma}

Adriano Beiras, Alex Lodetti, Arthur Grimm Cabral, Maria Juracy Filgueiras Toneli \& Pablo Raimundo 